\title{
SYNTHESIS OF FORMAMIDE AND RELATED ORGANIC SPECIES IN THE INTERSTELLAR MEDIUM VIA
} CHEMICAL DYNAMICS SIMULATIONS

\author{
Riccardo Spezia ${ }^{1}$, Yannick Jeanvoine ${ }^{1}$, William L. $\mathrm{Hase}^{2}$, Kihyung Song $^{3}$, and Antonio Largo ${ }^{4}$ \\ ${ }^{1}$ CNRS, Laboratoire Analyse et Modélisation pour la Biologie et l'Environnement, UMR 8587, Université d'Evry-Val-d'Essonne, \\ Evry, France; riccardo.spezia@univ-evry.fr \\ 2 Department of Chemistry and Biochemistry, Texas Tech University, Lubbock, TX 79409, USA \\ ${ }^{3}$ Department of Chemistry, Korea National University of Education, Chungbuk, Korea \\ ${ }^{4}$ Computational Chemistry Group, Departamento de Quimica Fisica, Facultad de Ciencias, Universidad de Valladolid, Valladolid, Spain \\ Received 2015 December 21; revised 2016 May 12; accepted 2016 May 23; published 2016 July 26
}

\begin{abstract}
We show, by means of direct dynamics simulations, how it is possible to define possible reactants and mechanisms leading to the formation of formamide in the interstellar medium. In particular, different ion-molecule reactions in the gas phase were considered: $\mathrm{NH}_{3} \mathrm{OH}^{+}, \mathrm{NH}_{2} \mathrm{OH}_{2}^{+}, \mathrm{H}_{2} \mathrm{COH}^{+}$, and $\mathrm{NH}_{4}^{+}$for the ions and $\mathrm{NH}_{2} \mathrm{OH}, \mathrm{H}_{2} \mathrm{CO}$, and $\mathrm{NH}_{3}$ for the partner neutrals. These calculations were combined with high level ab initio calculations to investigate possible further evolution of the products observed. In particular, for formamide, we propose that the $\mathrm{NH}_{2} \mathrm{OH}_{2}^{+}+$ $\mathrm{H}_{2} \mathrm{CO}$ reaction can produce an isomer, $\mathrm{NH}_{2} \mathrm{OCH}_{2}^{+}$, that, after dissociative recombination, can produce neutral formamide, which was observed in space. The direct dynamics do not pre-impose any reaction pathways and in other reactions, we did not observe the formation of formamide or any possible precursor. On the other hand, we obtained other interesting reactions, like the formation of $\mathrm{NH}_{2} \mathrm{CH}_{2}^{+}$. Finally, some radiative association processes are proposed. All of the results obtained are discussed in light of the species observed in radioastronomy.
\end{abstract}

Key words: astrobiology - astrochemistry - ISM: general - ISM: kinematics and dynamics - ISM: molecules molecular processes

\section{INTRODUCTION}

In recent years, interest in the presence of organic and biological molecules in space has grown considerably due to the increasing number of discoveries by modern radio telescopes and also by analyses of the compositions of meteorites and comets. If one is interested in molecules in the interstellar medium (ISM), the list of organic and biological molecules detected is continually becoming larger. In addition to the well-known disputed case of the simplest amino acid, glycine (Kuan et al. 2003; Snyder et al. 2005; Cunningham et al. 2007; Jones et al. 2007), there have also been detections of molecules with $(\mathrm{NH}-\mathrm{C}=\mathrm{O})$ peptide bond, like formamide (Rubin et al. 1971), acetamide (Hollis et al. 2006), and of other biologically relevant organic molecules like glycolaldehyde (the first sugar; Hollis et al. 2000), urea (Remijan et al. 2014), methyl acetate (Tercero et al. 2013), acetaldehyde (Gottlieb et al. 1973; Fourikis et al. 1974; Gilmore et al. 1976), and amino acetonitrile (Belloche et al. 2008).

Despite all these observations, the actual mechanisms leading to the formation of such molecules remains an open question. Astrophysical databases can be of help in determining some basic processes, but they rely on already known data and they do not provide any molecular information. Another possibe approach is to use quantum chemistry to rationalize the reactions leading to those molecules. Since molecules are very cold in the ISM, one idea is that the barrier should be very low, or better yet absent, to make the reaction possible. Although it is clear that the molecules are internally cold, it cannot be excluded that they have some translational energy. A gas phase bimolecular reaction, where the two products approach each other with some translational energy, may be at the origin of the formation of ISM species. For example, such events were suggested to be at the origin of formation of ketamine in the Sgr B2(N) region by Lovas et al. (2006), or of acetaldehyde in the hot core of Sgr B2 by Chengalur \& Kanekar (2003). In this region, other organic species such as formaldehyde (Whiteoak $\&$ Gardner 1983) and formamide (Rubin et al. 1971) were also observed. Sato et al. (2000) have postulated cloud-cloud collisions in this same region. Furthermore, this same region is characterized by a distorted magnetic field (Darren Dowell et al. 1998), which may be the origin of further acceleration of charged species. Thus, it is not unlikely that cold species may have non-negligible translational energy that may be partially converted into internal energy during a collision and allow some reactions to occur. This is the main working hypothesis of this article.

Bimolecular reactions can be studied both experimentally and theoretically. Experimentally, Kaiser and co-workers have studied different neutral-neutral reactions for formation of polycyclic aromatic hydrocarbons in the ISM (Kaiser 2002; Kaiser et al. 2015). The group of Bohme have studied ionmolecule reactions of the formation of different ions in the gas phase, mimicking ISM conditions (Petrie \& Bohme 2007); in particular, through gas phase ion-molecule reactions, they have produced carboxylic acid, glycine, and alanine (Blagojevic et al. 2003; Snow et al. 2007).

Theoretically, mainly "static" potential energy surface (PES) calculations have been used to investigate ion-molecule reactions of interest for the formation of different organic molecules observed in the ISM. To better explore complex PESs, Bera et al. (2015) have also used chemical dynamics simulations to study the formation of $\mathrm{C}_{4} \mathrm{H}_{2}^{+}, \mathrm{C}_{6} \mathrm{H}_{2}^{+}$, and $\mathrm{C}_{6} \mathrm{H}_{4}^{+}$. Such simulations illustrate the complexity of correctly exploring a reactive PES and often find that chemical reactions occur through regions of the PES not described by static PES calculations. Chemical dynamics simulations of bimolecular reactions have shown that a mere static study of the PES may be a limitation since reactions sometimes do not follow the minimum energy path on the PES (Lopez et al. 2007). For 
example, the production of high energy species observed experimentally may only be rationalized from explicit chemical dynamics simulations (Brites et al. 2015). In the context of bimolecular reactivity, a notable example is an $\mathrm{S}_{N} 2$ reaction that occurs by avoiding a deep minimum on the PES (Sun et al. 2002). A brief account of the applications of chemical dynamics simulations in the context of astrochemistry has been provided by Larsson et al. (2012) in their review on Ion Chemistry in Space.

Formamide, the simplest molecule bearing a peptide bond, is of course an interesting case to understand dynamical effects on reactivity and their relation to the formation of this molecule in the ISM. In particular, formamide has been detected in giant molecular clouds Sgr B2 (Rubin et al. 1971; Gottlieb et al. 1973; Halfen et al. 2011) and Orion-KL (Turner 1989). More recently, it has also been detected in the solar-type protostar IRAS 16293-2422 (Kahane et al. 2013). A recent study of Redondo et al. (2014a) has shown that the ion/ molecule reaction involving $\mathrm{NH}_{2} \mathrm{OH}_{2}^{+}$and $\mathrm{H}_{2} \mathrm{CO}$ may be the basis of the formation of this molecule, while other authors have suggested that it may be obtained by a ion-molecule reaction involving $\mathrm{H}_{2} \mathrm{CO}$ and $\mathrm{NH}_{4}^{+}$followed by dissociative electron recombination (Quan \& Herbst 2007; Halfen et al. 2011). Other studies have proposed neutral/neutral reactions, like those between $\mathrm{HCOOH}$ or $\mathrm{H}_{2} \mathrm{CO}$ with $\mathrm{NH}_{3}$ both in the gas phase and on ice of interstellar grains (Woon 2001a, 2001b). Some authors have proposed that the neutral-neutral reactions can produce formamide on grains, which are activated by irradiation (Garrod et al. 2008; Jones et al. 2011). Furthermore, a radical reaction between radical $\mathrm{NH}_{2}$ and $\mathrm{H}_{2} \mathrm{CO}$ was recently proposed from quantum chemistry calculations (Barone et al. 2015).

Here, we focus our attention on the simplest ion-molecule reactions between $\mathrm{NH}_{2} \mathrm{OH} / \mathrm{H}_{2} \mathrm{CO}$ and $\mathrm{NH}_{3} / \mathrm{H}_{2} \mathrm{CO}$ considering every possible protonated/neutral couple, stimulated by the aforementioned works, which suggested that these reactants may be the precursor for formamide synthesis in the ISM (Quan \& Herbst 2007; Halfen et al. 2011; Redondo et al. 2014a). In particular, simulations may be seen as theoretical laboratories in which one can perform reactions and analyze results at a relatively low cost. For that, the use of wavefunction- or DFT-based quantum chemistry can be a limitation when treating large molecular systems and the use of computationally fast semi-empirical Hamiltonians will be compulsory if we want to address the formation of larger molecules by chemical reaction dynamics. The systems studied here are probably the largest that can be treated in chemical reaction dynamics with wave-function- or DFT-based quantum chemistry and thus we can compare results done at the ab initio level with that obtained from a semi-empirical Hamiltonian.

Our aim is, thus, to use direct dynamics to see which ionmolecule reactions may be the basis of formamide formation in the ISM. Such simulations do not have any constraints, other than the electronic structure theory used for the simulations and the collision conditions, and the products formed are not controlled by a static search of the PES. In addition, one obtains detailed information regarding the molecular mechanisms responsible for the formation of the different products. Finally, such products may be discussed in light of what is observed by radioastronomy.

\section{COMPUTATIONAL METHODS}

\subsection{Quantum Chemistry Calculations}

All minima and transition states were obtained by quantum chemistry calculations at different levels of theory: MoellerPlesset theory (MP2) with two different basis sets, 6-31G(d,p) (Ditchfield et al. 1971) and aug-cc-pVTZ (Dunning 1989; Woon \& Dunning 1993), and the semi-empirical method MSINDO (Ahlswede \& Jug 1999a, 1999b). MSINDO was preferred to other semi-empirical Hamiltonians since it provides correct initial geometries and frequencies of the reactants and, as we will see, also reaction energies in relatively good agreement with MP2 and $\operatorname{CCSD}(\mathrm{T})$ calculations. For the optimized structures, vibrational analysis was performed to characterize the stationary points and to add zero-point energy (ZPE) to the electronic energy. Electronic energies were refined by single point calculations at the $\operatorname{CCSD}(\mathrm{T})$ level (Raghavachari et al. 1989) with the aug-cc-pVQZ basis set (Dunning 1989; Woon \& Dunning 1993) for the MP2/aug-cc-pVTZ geometries. The hydrogen abstraction reaction was performed by freezing the $\mathrm{C}-\mathrm{H}$ distance (which was assumed as the reaction coordinate) and optimizing the other coordinates at the MP2/aug-cc-pVTZ level of theory. The electronic energy was then refined with $\mathrm{CCSD}(\mathrm{T}) /$ aug-cc-pVQZ theory. The MP2 and $\operatorname{CCSD}(\mathrm{T})$ calculations were done with the Gaussian09 package (Frisch et al. 2009), while the MSINDO software was used for the MSINDO calculations (Bredow et al. 2009).

\subsection{Chemical Dynamics Simulations}

To simulate an ion-molecule reaction, we employed BornOppenheimer direct dynamics using the MP2/6-31G(d,p) and MSINDO levels of theory to calculate on-the-fly energies and gradients. In particular, given a bimolecular collision $\mathrm{A}+\mathrm{B}$, we generated initial conditions for separated $A$ and $B$ and then for the A $+\mathrm{B}$ collision as follows. For each molecule (A or B), we generated initial positions and momenta of the atoms by adding a quasi-classical $15 \mathrm{~K}$ Boltzmann distribution of vibrational/rotational energies about each minimum (obtained with the corresponding level of theory; Chapman \& Bunker 1975; Sloane \& Hase 1977; Cho et al. 1992). Energies for the normal modes of vibration were selected from a $15 \mathrm{~K}$ Boltzmann distribution and the resulting normal mode energies were partitioned between kinetic and potential energies by choosing a random phase for each normal mode. A $15 \mathrm{~K}$ rotational energy of RT/ 2 was added to each principal axis of rotation. The vibrational and rotational energies of each molecule were transformed into Cartesian coordinates and momenta following the well-known algorithms implemented in VENUS (Hase et al. 1996). Then, the A and B molecules were randomly rotated about their Euler angles to take into account the random orientations of the $\mathrm{A}+\mathrm{B}$ collisions. The relative velocity was then added to $\mathrm{A}+\mathrm{B}$ in accord with the center-ofmass collision energy (CE) and impact parameter. Different values of $\mathrm{CE}$, from 0.04 to $4.3 \mathrm{eV}$, were considered. The impact parameter was chosen randomly between 0 and $0.5 \AA$. Such small values were used to assure that a collision takes place.

The trajectories were calculated using the general chemical dynamics computer program VENUS (Hase et al. 1996) coupled to Gaussian09 (Frish et al. 2009) and MSINDO (Bredow et al. 2009) for the MP2 and MSINDO dynamics, respectively. The classical equations of motion were integrated using the velocity Verlet algorithm (Swope et al. 1982) with a 
Table 1

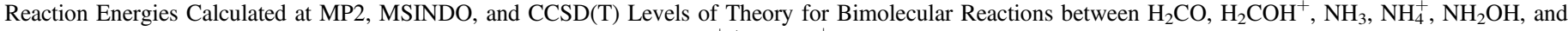
$\mathrm{NH}_{3} \mathrm{OH}^{+} / \mathrm{NH}_{2} \mathrm{OH}_{2}^{+}$Molecules

\begin{tabular}{|c|c|c|c|c|c|}
\hline \multirow[t]{2}{*}{ Reactant A } & \multirow[t]{2}{*}{ Reactant B } & \multirow[t]{2}{*}{ Products } & \multicolumn{3}{|c|}{$\Delta E^{(+\mathrm{ZPE})}(\mathrm{eV})$} \\
\hline & & & MP2//MP2/6-31G(d,p) & MSINDO//MSINDO & $\operatorname{CCSD}(\mathrm{T})^{\mathrm{a}}$ \\
\hline $\mathrm{NH}_{3} \mathrm{OH}^{+}$ & $\mathrm{H}_{2} \mathrm{CO}$ & $\mathrm{H}_{2} \mathrm{COH}^{+}+\mathrm{NH}_{2} \mathrm{OH}$ & +1.21 & +1.13 & +1.07 \\
\hline $\mathrm{NH}_{2} \mathrm{OH}_{2}^{+}$ & $\mathrm{H}_{2} \mathrm{CO}$ & $\mathrm{H}_{2} \mathrm{COH}^{+}+\mathrm{NH}_{2} \mathrm{OH}$ & +0.09 & -0.05 & -0.04 \\
\hline $\mathrm{NH}_{2} \mathrm{OH}_{2}^{+}$ & $\mathrm{H}_{2} \mathrm{CO}$ & $\mathrm{H}_{2} \mathrm{CO}+\mathrm{NH}_{3} \mathrm{OH}^{+}$ & -1.12 & -1.19 & -1.11 \\
\hline $\mathrm{NH}_{2} \mathrm{OH}_{2}^{+}$ & $\mathrm{H}_{2} \mathrm{CO}$ & $\mathrm{NH}_{2} \mathrm{OCH}_{2}^{+}+\mathrm{H}_{2} \mathrm{O}$ & -0.87 & -1.56 & -0.91 \\
\hline $\mathrm{NH}_{2} \mathrm{OH}$ & $\mathrm{H}_{2} \mathrm{COH}^{+}$ & $\mathrm{NH}_{3} \mathrm{OH}^{+}+\mathrm{H}_{2} \mathrm{CO}$ & -1.21 & -1.13 & -1.07 \\
\hline $\mathrm{NH}_{2} \mathrm{OH}$ & $\mathrm{H}_{2} \mathrm{COH}^{+}$ & $\mathrm{H}_{2} \mathrm{CO}+\mathrm{NH}_{2} \mathrm{OH}_{2}^{+}$ & -0.09 & +0.05 & +0.04 \\
\hline $\mathrm{NH}_{2} \mathrm{OH}$ & $\mathrm{H}_{2} \mathrm{COH}^{+}$ & $\mathrm{CH}_{2} \mathrm{OHNH}_{2} \mathrm{OH}^{+}$ & -2.10 & -2.10 & -2.04 \\
\hline $\mathrm{NH}_{4}^{+}$ & $\mathrm{H}_{2} \mathrm{CO}$ & $\mathrm{H}_{2} \mathrm{COH}^{+}+\mathrm{NH}_{3}$ & +1.70 & +1.70 & +1.44 \\
\hline $\mathrm{NH}_{4}^{+}$ & $\mathrm{H}_{2} \mathrm{CO}$ & $\mathrm{NH}_{2} \mathrm{CHOH}^{+}+\mathrm{H}_{2}{ }^{\mathrm{b}}$ & -0.12 & -0.43 & -0.16 \\
\hline $\mathrm{NH}_{4}^{+}$ & $\mathrm{H}_{2} \mathrm{CO}$ & $\mathrm{NH}_{3} \mathrm{CHO}^{+}+\mathrm{H}_{2}{ }^{\mathrm{b}}$ & +0.48 & -0.12 & +0.56 \\
\hline $\mathrm{NH}_{4}^{+}$ & $\mathrm{H}_{2} \mathrm{CO}$ & $\mathrm{NH}_{3} \mathrm{CH}_{2} \mathrm{OH}^{+}+\mathrm{H}_{2}^{\mathrm{b}}$ & -0.58 & -1.14 & -0.69 \\
\hline $\mathrm{NH}_{3}$ & $\mathrm{H}_{2} \mathrm{COH}^{+}$ & $\mathrm{NH}_{4}^{+}+\mathrm{H}_{2} \mathrm{CO}$ & -1.70 & -1.70 & -1.44 \\
\hline $\mathrm{NH}_{3}$ & $\mathrm{H}_{2} \mathrm{COH}^{+}$ & $\mathrm{NH}_{3} \mathrm{CH}_{2} \mathrm{OH}^{+}$ & -2.29 & -2.84 & -2.13 \\
\hline $\mathrm{NH}_{3}$ & $\mathrm{H}_{2} \mathrm{COH}^{+}$ & $\mathrm{NH}_{2} \mathrm{CH}_{2}^{+}+\mathrm{H}_{2} \mathrm{O}$ & -1.57 & -1.90 & -1.59 \\
\hline
\end{tabular}

Notes. We considered reactions observed in chemical dynamics as well as some reactions that can be conceived, but not necessarily observed, in dynamics.

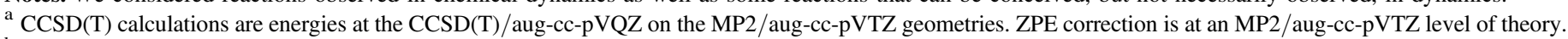

${ }^{\mathrm{b}}$ Reactions not observed in chemical dynamics simulations.

time step of $0.2 \mathrm{fs}$ for MP2 and $0.1 \mathrm{fs}$ for MSINDO, thus obtaining good energy conservation and relatively fast simulations (for MP2, we used 0.2 fs because it is the best compromise between quality of results and computing time; Spezia et al. 2009). The trajectories were initiated at an A-B distance of $8.0 \AA$ and halted when the products were at a distance of $10 \AA$, for a simulation time between approximately $250 \mathrm{fs}$ and $1.2 \mathrm{ps}$, depending on $\mathrm{CE}$ (for low CE, we have longer trajectories). Trajectories for which SCF convergence was not attained were disregarded. Since we need to sample a distribution of initial conditions for the trajectories, we calculated an ensemble of trajectories. In particular, for the MP2/6-31G(d,p) simulations, we calculated around 60 trajectories for each energy and for each system studied, while for the MSINDO dynamics, we calculated around 1000 trajectories for each case. With MP2/6-31G(d,p), each trajectory costs more than one day of calculations per core on an Intel Xeon X7350, while with MSINDO, we calculated about 50 trajectories in one day.

\section{RESULTS AND DISCUSSIONS}

\subsection{Reactions Observed}

The energetics of ion-molecule reactions observed in the chemical dynamics simulations are summarized in Table 1 (where we also report some reactions not observed in the simulations, but suggested as possible reaction channels). In the same table, we compare the MP2/6-31G(d,p) and MSINDO results (the methods used in the direct dynamics) with those obtained by high level $\operatorname{CCSD}(\mathrm{T}) / / \mathrm{MP} 2$ calculations. In most cases, both MP2 and MSINDO provide energies very close to the reference $\operatorname{CCSD}(\mathrm{T})$ calculations, with some exceptions. In one case of proton transfer, MP2 provides an opposite sign with respect to CCSD(T) and MSINDO, while for another $\left(\mathrm{H}_{2}\right.$ loss) it is MSINDO that provides an opposite sign with respect to $\operatorname{CCSD}(\mathrm{T})$ and MP2.

In some cases, two reactants can provide different reaction pathways, while in other cases they lead to only one product. In particular, the reaction of $\mathrm{NH}_{3} \mathrm{OH}^{+}$with $\mathrm{H}_{2} \mathrm{CO}$ has a very low reaction yield (about 5\% with MP2 and 3\% with MSINDO and occurs only for a high $\mathrm{CE}$ of $4.3 \mathrm{eV}$ ). The only reaction observed is the simple proton transfer

$$
\mathrm{NH}_{3} \mathrm{OH}^{+}+\mathrm{H}_{2} \mathrm{CO} \rightarrow \mathrm{NH}_{2} \mathrm{OH}+\mathrm{H}_{2} \mathrm{COH}^{+} \text {. }
$$

Since the reaction is endothermic, it is normal that it is observed only for relatively high $\mathrm{CE}$. It is not surprising that $\mathrm{NH}_{3} \mathrm{OH}^{+}$is not reactive, since it is the most stable isomer. The PES study of Largo and co-workers has already pointed out that it is unlikely that $\mathrm{NH}_{3} \mathrm{OH}^{+}$will react to produce formamide (Redondo et al. 2014a). Thus, if we assume that this isomer is formed in the ISM, the only expected reaction in the presence of $\mathrm{H}_{2} \mathrm{CO}$ is proton transfer and thus the formation of neutral $\mathrm{NH}_{2} \mathrm{OH}$ and the $\mathrm{H}_{2} \mathrm{COH}^{+}$ion. We will discuss the possible further reactivity of these products later.

The other isomer, $\mathrm{NH}_{2} \mathrm{OH}_{2}^{+}$, is much more reactive, as already pointed out in static calculations (Redondo et al. 2014a). Our dynamics show that four products are obtained: two proton transfers, loss of water, and formation of $\mathrm{NH}_{2} \mathrm{OCH}_{2}^{+}$, which is an isomeric form of protonated formamide. These reactions are exothermic and thus it is not surprising they are observed. We will discuss them in detail in Section 3.2.1.

The reactions of $\mathrm{NH}_{2} \mathrm{OH}_{2}^{+}$with $\mathrm{H}_{2} \mathrm{CO}$ have shown that a proton transfer between the two molecules is possible, thus forming $\mathrm{NH}_{2} \mathrm{OH}$ and $\mathrm{H}_{2} \mathrm{COH}^{+}$. Note that even if this reaction shows a different energy sign in MP2 and MSINDO, it is observed in both simulations, probably because the endothermicity of MP2 is relatively small. In any case, $\mathrm{H}_{2} \mathrm{COH}^{+}$, protonated formaldehyde, has been detected in 1996 in the same molecular clouds where formamide was observed, Sgr B2 and Orion-KL (Ohishi et al. 1996). Another reaction, not considered in the previous studies, is the reaction of protonated formaldehyde with $\mathrm{NH}_{2} \mathrm{OH}$. These two molecules can be obtained by reaction (1), though they can have other origins. What we observed in the simulations were three products, two proton transfers, and the formation of hydroxyl-ammoniummethanol $\left(\mathrm{CH}_{2} \mathrm{OHNH}_{2} \mathrm{OH}^{+}\right)$. This last reaction is exothermic and thus it was not surprising that it was observed. We will 
detail the dynamics of the formation of those products in Section 3.2.2.

Finally, we also studied the reactions of $\mathrm{H}_{2} \mathrm{CO}$ with $\mathrm{NH}_{4}^{+}$ and $\mathrm{H}_{2} \mathrm{COH}^{+}$with $\mathrm{NH}_{3}$. The first reaction can, in principle, lead to formamide, by losing $\mathrm{H}_{2}$, but we observed only the simple proton transfer

$$
\mathrm{NH}_{4}^{+}+\mathrm{H}_{2} \mathrm{CO} \rightarrow \mathrm{NH}_{3}+\mathrm{H}_{2} \mathrm{COH}^{+} .
$$

This reaction is endothermic, and we observed it with a low probability $(1.7 \%)$ at a relatively high collision energy (4.3 $\mathrm{eV}$ ). The reactions leading to $\mathrm{H}_{2}$ and $\mathrm{NH}_{2} \mathrm{CHOH}^{+}$or $\mathrm{NH}_{3} \mathrm{CHO}^{+}$were never observed in either the MP2 or MSINDO simulations. Note that the formation of $\mathrm{NH}_{2} \mathrm{CHOH}^{+}$with $\mathrm{H}_{2}$ loss is exothermic, but it has a high activation barrier and needs a complex molecular rearrangement that has a low probability during the collision. A detailed analysis of the PES for $\mathrm{NH}_{2} \mathrm{CHOH}^{+}+\mathrm{H}_{2}$ formation was reported by Redondo et al. (2014b), where it was shown that the evolution of the initially formed complex takes place through paths involving high barriers (from the energy of the corresponding transition states). Furthermore, the $\mathrm{NH}_{3} \mathrm{CHO}^{+}+\mathrm{H}_{2}$ reaction that is exothermic with MSINDO, while endothermic with MP2 and $\operatorname{CCSD}(\mathrm{T})$, was never observed, such that the partial incorrectness of MSINDO has no effect on the reaction products.

The other reaction, $\mathrm{NH}_{3}+\mathrm{H}_{2} \mathrm{COH}^{+}$, has three pathways: (1) proton transfer, (2) formation of protonated aminomethanol, $\mathrm{NH}_{3} \mathrm{CH}_{2} \mathrm{OH}^{+}$, and (3) loss of $\mathrm{H}_{2} \mathrm{O}$ and formation of $\mathrm{NH}_{2} \mathrm{CH}_{2}^{+}$. All these reaction pathways are exothermic. These mechanisms are described in detail in Section 3.2.3.

\subsection{Bimolecular Reaction Dynamics}

We now discuss the products obtained in collisions for the different ion-molecule reactions. In particular, we will describe in detail reactions leading to more than one product. Reactions (1) and (2) are not particularly interesting because they show a low reaction probability and what occurs is only a proton exchange. Conversely, the reactions of $\mathrm{NH}_{2} \mathrm{OH}_{2}^{+}$with $\mathrm{H}_{2} \mathrm{CO}$ and of $\mathrm{H}_{2} \mathrm{COH}^{+}$with $\mathrm{NH}_{2} \mathrm{OH}$ and $\mathrm{NH}_{3}$ show interesting products and mechanisms that we discuss in the following.

$$
\text { 3.2.1. } \mathrm{NH}_{2} \mathrm{OH}_{2}^{+}+\mathrm{H}_{2} \mathrm{CO}
$$

The reaction of $\mathrm{NH}_{2} \mathrm{OH}_{2}^{+}$, the high energy tautomer of protonated $\mathrm{NH}_{2} \mathrm{OH}$, with $\mathrm{H}_{2} \mathrm{CO}$ is one of the most interesting reactions. It was already suggested that the less stable isomer of protonated hydroxylamine, $\mathrm{NH}_{2} \mathrm{OH}_{2}^{+}$, could react with $\mathrm{H}_{2} \mathrm{CO}$ to provide protonated formamide, by an investigation of the PES (Redondo et al. 2014a). Here, in chemical dynamics simulations of bimolecular reactions, the system is not constrained to follow any pre-determined reaction pathway and we observed the following three reaction channels:

$$
\begin{gathered}
\mathrm{NH}_{2} \mathrm{OH}_{2}^{+}+\mathrm{H}_{2} \mathrm{CO} \rightarrow \mathrm{NH}_{2} \mathrm{OH}+\mathrm{H}_{2} \mathrm{COH}^{+} \\
\mathrm{NH}_{2} \mathrm{OH}_{2}^{+}+\mathrm{H}_{2} \mathrm{CO} \rightarrow \mathrm{NH}_{3} \mathrm{OH}^{+}+\mathrm{H}_{2} \mathrm{CO} \\
\mathrm{NH}_{2} \mathrm{OH}_{2}^{+}+\mathrm{H}_{2} \mathrm{CO} \rightarrow \mathrm{NH}_{2} \mathrm{OCH}_{2}^{+}+\mathrm{H}_{2} \mathrm{O} .
\end{gathered}
$$

To characterize these reactions it is interesting to study the reactivity as a function of the CE, as shown in Figure 1. The behavior of the percentage of non-reactive trajectories is not surprising. Increasing the energy is not always expected to increase the reactivity. While increasing the collision energy gives more probability to pass some reaction barrier, the attractive interaction between the ion and neutral reactants

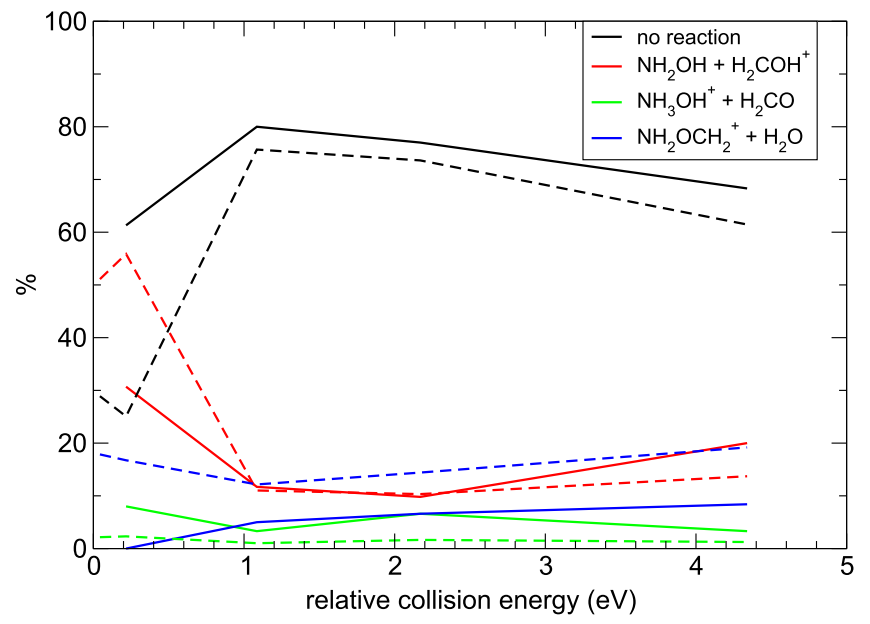

Figure 1. $\mathrm{NH}_{2} \mathrm{OH}_{2}^{+}+\mathrm{H}_{2} \mathrm{CO}$ reaction chemical dynamics results. The percentage of different reaction products is shown as a function of relative collision energy: MP2 (full lines) and MSINDO (dashed lines) calculations.

becomes less important with increasing CE. Thus the reaction probability may decrease because the two reactants have less time to interact. An example of this phenomenon is given by reaction (3), in which increasing the $\mathrm{CE}$ decreases the reaction probability, and it shows a maximum at low CE. Reaction (4) has a very low probability, even though it forms the most stable $\mathrm{NH}_{3} \mathrm{OH}^{+}$isomer, because the mechanism is relatively complex: it needs two proton transfers, one from $\mathrm{NH}_{2} \mathrm{OH}_{2}^{+}$to $\mathrm{H}_{2} \mathrm{CO}$ and another from the formed $\mathrm{H}_{2} \mathrm{COH}^{+}$to $\mathrm{NH}_{2} \mathrm{OH}$. This mechanism may have a substantial barrier and the two reactants may need to spend sufficient time together for the two processes to occur.

Reaction (5) is the most interesting since it forms $\mathrm{NH}_{2} \mathrm{OCH}_{2}^{+}$, an isomer of protonated formamide. The reaction is relatively fast. It happens in about $100 \mathrm{fs}$, and an example is shown in Figure 2(a): $\mathrm{H}_{2} \mathrm{CO}$ needs to interact with the $-\mathrm{NH}_{2}$ group, which then rotates, breaking the $\mathrm{N}-\mathrm{O}$ bond and forming a new $\mathrm{N}-\mathrm{C}$ bond. The mechanism is different from that reported previously by Largo and co-workers using a static PES analysis for the same reaction (Redondo et al. 2014a): it is not uncommon that a reaction does not occur along the minimum energy path (Sun et al. 2002), in particular, when energy is provided to the system. This reaction is observed with MP2 dynamics when $\mathrm{CE}>1 \mathrm{eV}$, while the MSINDO dynamics also yield this isomer at low energies. Note that, with some exceptions, the MSINDO and MP2 chemical dynamics are similar not only in determining which products are obtained, but also in the product percentages as a function of CE. The $\mathrm{NH}_{2} \mathrm{OCH}_{2}^{+}$ion is stable within the timescale of the simulations. To study its stability in more detail, simulations were performed for isolated $\mathrm{NH}_{2} \mathrm{OCH}_{2}^{+}$with an added internal energy of 2.9 or $3.2 \mathrm{eV}$ (these values correspond to the internal energy of some $\mathrm{NH}_{2} \mathrm{OCH}_{2}^{+}$ions obtained from the bimolecular simulations). No dissociation of the ion was observed for trajectories integrated as long as 4 ps with MP2. In Section 3.3, we suggest some possible mechanisms to obtain protonated formamide and neutral formamide from this ion.

\subsection{2. $\mathrm{NH}_{2} \mathrm{OH}+\mathrm{H}_{2} \mathrm{COH}^{+}$}

We have shown (reaction (1)) that $\mathrm{NH}_{3} \mathrm{OH}^{+}$, the most stable ion, can react with $\mathrm{H}_{2} \mathrm{CO}$, forming $\mathrm{NH}_{2} \mathrm{OH}$ and $\mathrm{H}_{2} \mathrm{COH}^{+}$. 
a)

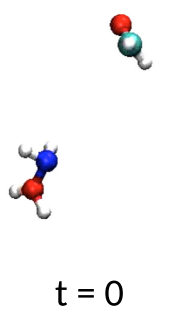

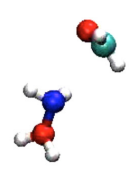

$t=30 \mathrm{fs}$

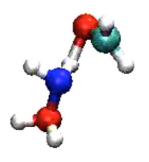

$t=84 \mathrm{fs}$

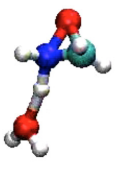

$t=100 \mathrm{fs}$

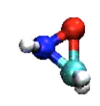

8

$t=120 \mathrm{fs}$

b)
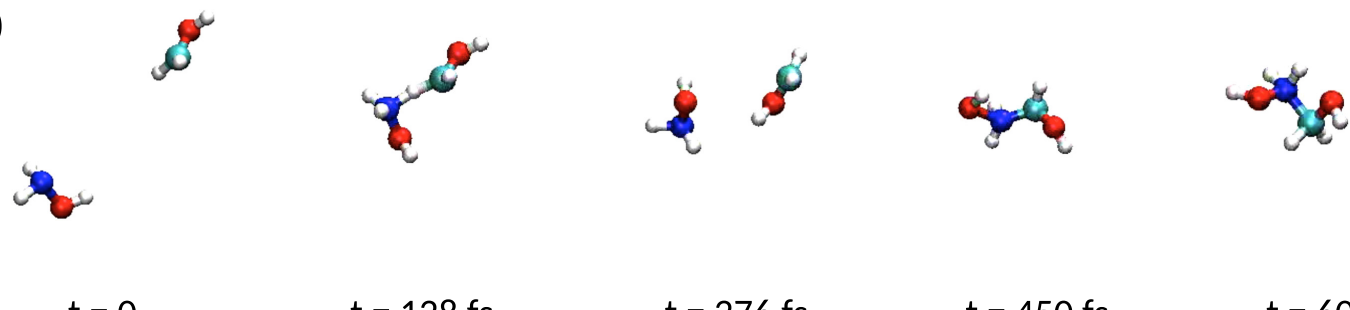

$\mathrm{t}=0$

$\mathrm{t}=128 \mathrm{fs}$

$\mathrm{t}=276 \mathrm{fs}$

$\mathrm{t}=450 \mathrm{fs}$

$\mathrm{t}=600 \mathrm{fs}$

Figure 2. Snapshots from selected MP2 chemical dynamics trajectories: (a) $\mathrm{NH}_{2} \mathrm{OH}_{2}^{+}+\mathrm{H}_{2} \mathrm{CO} \rightarrow \mathrm{NH}_{2} \mathrm{OCH}_{2}^{+}+\mathrm{H}_{2} \mathrm{O}$. (b) $\mathrm{NH}_{2} \mathrm{OH}+\mathrm{H}_{2} \mathrm{COH}^{+} \rightarrow \mathrm{CH}_{2} \mathrm{OHNH}_{2} \mathrm{OH}^{+}$.

These species can also be formed from other processes in the ISM, and therefore their origin is not limited to reaction (1). If we perform bimolecular collisions between these species, we observed the following reactions:

$$
\begin{gathered}
\mathrm{NH}_{2} \mathrm{OH}+\mathrm{H}_{2} \mathrm{COH}^{+} \rightarrow \mathrm{NH}_{3} \mathrm{OH}^{+}+\mathrm{H}_{2} \mathrm{CO} \\
\mathrm{NH}_{2} \mathrm{OH}+\mathrm{H}_{2} \mathrm{COH}^{+} \rightarrow \mathrm{NH}_{2} \mathrm{OH}_{2}^{+}+\mathrm{H}_{2} \mathrm{CO} \\
\mathrm{NH}_{2} \mathrm{OH}+\mathrm{H}_{2} \mathrm{COH}^{+} \rightarrow \mathrm{CH}_{2} \mathrm{OHNH}_{2} \mathrm{OH}^{+} .
\end{gathered}
$$

Reactions (6) and (7) are typical proton transfers that do not provide any new and interesting molecules. However, reaction (8) which produces hydroxyl-ammonium-methanol, $\mathrm{CH}_{2} \mathrm{OHNH}_{2} \mathrm{OH}^{+}$is interesting. In Figure 3, we show MP2 and MSINDO results in terms of product percentages as a function of $\mathrm{CE}$, where it is seen that increasing $\mathrm{CE}$ decreases the reactivity: the best conditions are at low CE. This is relevant, in particular, for the formation of hydroxyl-ammonium-methanol. This molecule has not been observed in the ISM. We will see, in Section 3.2.3, the formation of protonated aminomethanol by replacing $\mathrm{NH}_{2} \mathrm{OH}$ with $\mathrm{NH}_{3}$. An example of the dynamics leading to $\mathrm{CH}_{2} \mathrm{OHNH}_{2} \mathrm{OH}^{+}$is shown in Figure 2 (b), which includes the structure of the final product: this reaction is relatively slow (about $600 \mathrm{fs}$ ) and is why its probability decreases when $\mathrm{CE}$ increases: the two molecules need time to exchange a proton, form a complex, and make a new $\mathrm{C}-\mathrm{N}$ bond. Reaction (8) is an exothermic association process that in the ISM needs to lose the excess energy. One possible pathway, analogous to what is suggested for the formation of methylamine and methanol (Huntress \& Mitchell 1979; Herbst 1985a, 1985b) is emission of a photon, so that the reaction (8) may be rewritten in a typical astrophysical context as

$$
\mathrm{NH}_{2} \mathrm{OH}+\mathrm{H}_{2} \mathrm{COH}^{+} \rightarrow \mathrm{CH}_{2} \mathrm{OHNH}_{2} \mathrm{OH}^{+}+h \nu .
$$

Since the reaction is exothermic, the product needs to dissipate energy to be stabilized. In these particular cases, the mechanism for radiative stabilization should be a vibrational relaxation by emitting an infra-red photon. Evaluation of the rate coefficient for radiative stabilization, $k_{r}$, (following the simple approach of Herbst 1982) provides values of $39 \mathrm{~s}^{-1}$ for the threshold energy, being on the typical order of magnitude of

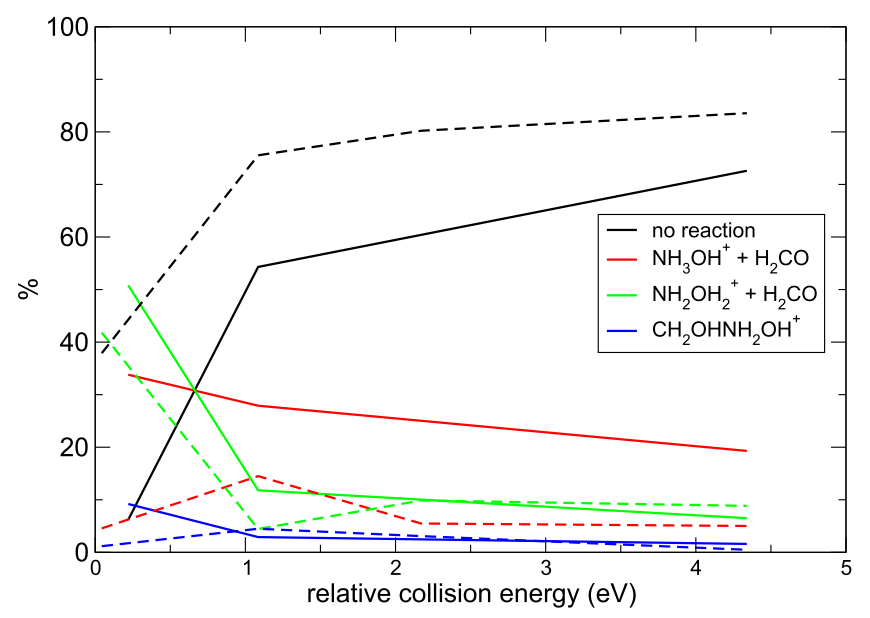

Figure 3. $\mathrm{NH}_{2} \mathrm{OH}+\mathrm{H}_{2} \mathrm{COH}^{+}$reaction chemical dynamics results. The percentage of different reaction products is shown as a function of relative collision energy: MP2 (full lines) and MSINDO (dashed lines) calculations.

other organic molecules. The abundance of $\mathrm{CH}_{2} \mathrm{OHNH}_{2} \mathrm{OH}^{+}$ in our simulations is low. This can provide an argument to look for $\mathrm{CH}_{2} \mathrm{OHNH}_{2} \mathrm{OH}^{+}$in the ISM.

$$
\text { 3.2.3. } \mathrm{NH}_{3}+\mathrm{H}_{2} \mathrm{COH}^{+}
$$

Finally, another route to obtain formamide, in principle, is by the reaction of $\mathrm{NH}_{3}$ with $\mathrm{H}_{2} \mathrm{CO}$. We have studied the two corresponding ion/neutral bimolecular collisions. The first, $\mathrm{NH}_{4}^{+}+\mathrm{H}_{2} \mathrm{CO}$ was discussed in Section 3.1 and it does not provide any interesting results. The other, $\mathrm{NH}_{3}+\mathrm{H}_{2} \mathrm{COH}^{+}$, is much more interesting since we obtained different reactions. In particular, we observed

$$
\begin{gathered}
\mathrm{NH}_{3}+\mathrm{H}_{2} \mathrm{COH}^{+} \rightarrow \mathrm{NH}_{4}^{+}+\mathrm{H}_{2} \mathrm{CO} \\
\mathrm{NH}_{3}+\mathrm{H}_{2} \mathrm{COH}^{+} \rightarrow \mathrm{NH}_{3} \mathrm{CH}_{2} \mathrm{OH}^{+} \\
\mathrm{NH}_{3}+\mathrm{H}_{2} \mathrm{COH}^{+} \rightarrow \mathrm{NH}_{2} \mathrm{CH}_{2}^{+}+\mathrm{H}_{2} \mathrm{O} .
\end{gathered}
$$

Reaction (9) is a typical proton transfer that does not provide any interesting products, while reactions (10) and (11) are quite interesting. Reaction (10) forms protonated aminomethanol. 


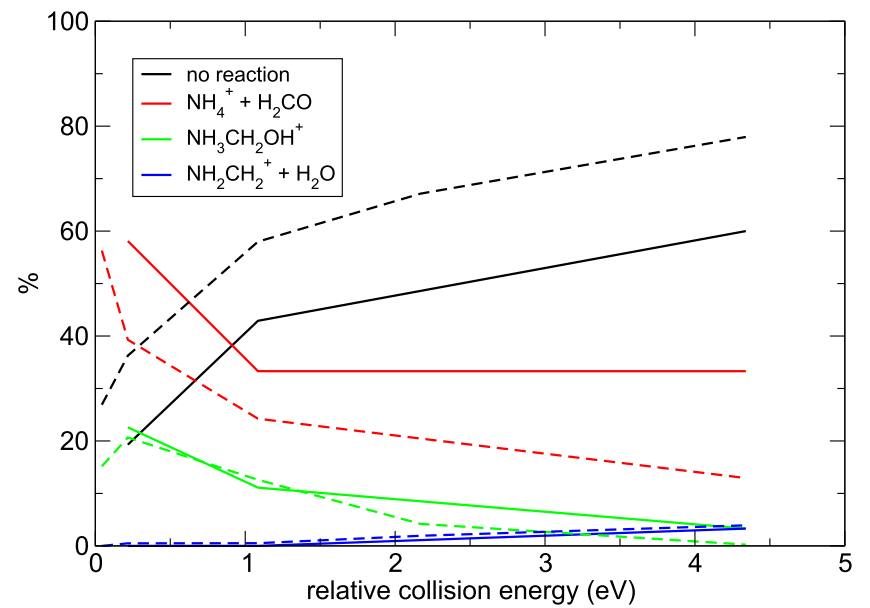

Figure 4. $\mathrm{NH}_{3}+\mathrm{H}_{2} \mathrm{COH}^{+}$reaction chemical dynamics results. The percentage of different reaction products is shown as a function of relative collision energy: MP2 (full lines) and MSINDO (dashed lines) calculations.

This is coherent with the results of Woon (1999), who suggested from PES calculations that the neutral/neutral reaction will lead to aminomethanol, but not formamide. Furthermore, Quan \& Herbst (2007) have attempted to produce formamide by ion-molecule reactions $\left(\mathrm{NH}_{4}^{+}+\mathrm{H}_{2} \mathrm{CO}\right)$, but they never obtained a reasonable abundance, thus concluding that this pathway is not responsible for the formation of formamide. Our simulations of the corresponding ion/neutral reaction show that protonated aminomethanol can be formed, but we did not observe any $\mathrm{H}_{2}$ loss, leading to protonated formamide. Furthermore, reaction (10) is an associative process that in the ISM may be followed by radiation emission, such that it may be rewritten as

$$
\mathrm{NH}_{3}+\mathrm{H}_{2} \mathrm{COH}^{+} \rightarrow \mathrm{NH}_{3} \mathrm{CH}_{2} \mathrm{OH}^{+}+h \nu
$$

The radiative association process leading to the formation of stable $\mathrm{NH}_{3} \mathrm{CH}_{2} \mathrm{OH}^{+}$would be the same for $\mathrm{CH}_{2} \mathrm{OHNH}_{2} \mathrm{OH}^{+}$ with a $k_{r}$ of $63 \mathrm{~s}^{-1}$.

On the other hand, we observed another possible reaction, corresponding to the neutral loss and formation of $\mathrm{NH}_{2} \mathrm{CH}_{2}^{+}$ (reaction (11)). This molecule has not yet been observed in the ISM, but it may be the precursor for other reactions. In particular, we suggest two possible reactions: (1) a dissociative recombination process forming $\mathrm{CH}_{2} \mathrm{NH}$ (this species was observed in 1973 (Godfrey et al. 1973)):

$$
\mathrm{NH}_{2} \mathrm{CH}_{2}^{+}+e^{-} \rightarrow \mathrm{NH}_{2} \mathrm{CH}+\mathrm{H}
$$

and (2) a reaction with $\mathrm{CN}^{-}$(a negative species observed in 2010; Agundez et al. 2010) forming $\mathrm{NH}_{2} \mathrm{CH}_{2} \mathrm{CN}$, (which was observed in 2008; Belloche et al. 2008) via a radiative association process:

$$
\mathrm{NH}_{2} \mathrm{CH}_{2}^{+}+\mathrm{CN}^{-} \rightarrow \mathrm{NH}_{2} \mathrm{CH}_{2} \mathrm{CN}+h \nu \text {. }
$$

The formation of $\mathrm{NH}_{2} \mathrm{CH}_{2} \mathrm{CN}$ is highly exothermic $(\Delta E=-7.2 \mathrm{eV}$ at $\mathrm{MP} 2 /$ aug-cc-pVTZ//CCSD(T)/aug-ccpVTZ level of theory) such that the radiative stabilization can be vibrational (with a $k_{r}$ of $29 \mathrm{~s}^{-1}$ ), but the implication of excited states cannot be ruled out, since the first excited state is evaluated at about $6 \mathrm{eV}$ (from time dependent DFT calculations at B3LYP/6-311++G(d,p) level of theory).

The percentage of each reaction channel, (9)-(11), as a function of $\mathrm{CE}$ is shown in Figure 4. Furthermore, in this case, the reactivity decreases with increasing $\mathrm{CE}$ with the exception of reaction (11): the water loss process, similar to reaction (5), needs energy.

\subsection{Formation of Formamide from $\mathrm{NH}_{2} \mathrm{OCH}_{2}^{+}$Intermediate}

From reaction (5) we obtained an isomer of protonated formamide, $\mathrm{NH}_{2} \mathrm{OCH}_{2}^{+}$. Up to now, no evidence of this particular isomer of protonated formamide is reported by radioastronomy. Possible subsequent reactions of $\mathrm{NH}_{2} \mathrm{OCH}_{2}^{+}$ are isomerizations. A first possible isomerization is a proton transfer to the oxygen atom, breaking the NCO three-atom ring and forming the $\mathrm{NH}_{2} \mathrm{CHOH}^{+}$species, which is more stable by $3.26 \mathrm{eV}$ with respect to $\mathrm{NH}_{2} \mathrm{OCH}_{2}^{+}$. Another possibility is to form the other isomer with a protonated nitrogen atom, $\mathrm{NH}_{3} \mathrm{CHO}^{+}$. Both species can then evolve forming $\mathrm{NH}_{2} \mathrm{CO}^{+}$ and $\mathrm{H}_{2}$. The energetics of these reactions as obtained with CCSD $(\mathrm{T})$ are reported in Figure 5(a). Unfortunately, it was not possible to locate any transition state connecting $\mathrm{NH}_{2} \mathrm{OCH}_{2}^{+}$ with $\mathrm{NH}_{2} \mathrm{CHOH}^{+}$, probably because this is a complex direct path (of course the possibility of hydrogen tunneling cannot be disregarded). This is in agreement with our dynamics for $\mathrm{NH}_{2} \mathrm{OCH}_{2}^{+}$, with excess internal energy, where no reactivity was observed. Thus, to reach the stable $\mathrm{NH}_{2} \mathrm{CHOH}^{+}$isomer, the system may need to first isomerize to $\mathrm{NH}_{3} \mathrm{CHO}^{+}$, needing $1.85 \mathrm{eV}$ to reach the transition state. Then the $\mathrm{NH}_{3} \mathrm{CHO}^{+}$ isomer may evolve either to the stable $\mathrm{NH}_{2} \mathrm{CHOH}^{+}$species or break into $\mathrm{H}_{2}$ and $\mathrm{NH}_{2} \mathrm{CO}^{+}$. Note that $\mathrm{NH}_{2} \mathrm{CHOH}^{+}$may also break into $\mathrm{H}_{2}$ and $\mathrm{NH}_{2} \mathrm{CO}^{+}$. In both cases, the barriers to break into $\mathrm{H}_{2}$ and $\mathrm{NH}_{2} \mathrm{CO}^{+}$are smaller than the $1.85 \mathrm{eV}$ barrier needed to isomerize the $\mathrm{NH}_{2} \mathrm{OCH}_{2}^{+}$species. Thus, one may argue that once this isomerization process is attained, the system should break into $\mathrm{H}_{2}$ and $\mathrm{NH}_{2} \mathrm{CO}^{+}$. The $\mathrm{NH}_{2} \mathrm{CO}^{+}$ species was proposed to be present in Sgr B2(N) in 2013 (Gupta et al. 2013; and interstellar $\mathrm{H}_{2}$ was observed in 1970; Carruthers 1970) thus strengthening the view that if the isomerization pathway is followed, then it is likely that $\mathrm{NH}_{2} \mathrm{CO}^{+}$will be obtained instead of formamide. Thus, the above reactivity needs $1.85 \mathrm{eV}$ of internal energy. Assuming that $\mathrm{NH}_{2} \mathrm{OCH}_{2}^{+}$is formed from the bimolecular reaction, this energy can come from residual collision energy that is converted into internal energy of the product. Our simulations show that $\mathrm{NH}_{2} \mathrm{OCH}_{2}^{+}$obtained in this way may have enough energy to isomerize.

Another possibility is that the $\mathrm{NH}_{2} \mathrm{OCH}_{2}^{+}$isomer reacts via a recombinant dissociation process:

$$
\mathrm{NH}_{2} \mathrm{OCH}_{2}^{+}+e^{-} \rightarrow \mathrm{NH}_{2} \mathrm{CH}_{2} \mathrm{O} \rightarrow \mathrm{NH}_{2} \mathrm{CHO}+\mathrm{H} \text {. }
$$

The first step is the formation of neutral doublet $\mathrm{NH}_{2} \mathrm{OCH}_{2}$ : when we optimize its structure, it spontaneously opens to form $\mathrm{NH}_{2} \mathrm{CH}_{2} \mathrm{O}$. Then, this species can lose one hydrogen atom to form neutral formamide. This process is schematized in Figure 5(b). The hydrogen-atom abstraction energy profile was studied and is reported in Figure 5(c): the system needs less than $1 \mathrm{eV}$ to pass the $\mathrm{H}$-abstraction barrier. Thus, this process needs less excess energy than the isomerization. The picture emerging is that it is sufficient to form $\mathrm{NH}_{2} \mathrm{OCH}_{2}^{+}$ without much internal excess energy from a bimolecular process to obtain formamide in astrophysical conditions. In fact, if this species then encounters an electron, the system has enough internal energy to form neutral formamide. 
a)<smiles>C1[NH+]O1</smiles>

(a)

[0.0]<smiles>[2H][NH+]([2H])C=O</smiles>

(c)

$[-2.54]$
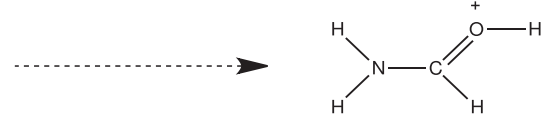

(b)

$[-3.26]$

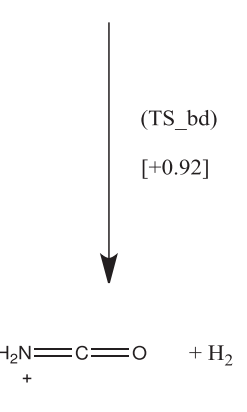

$[+1.64]$

(d)

$[-1.46]$ c)

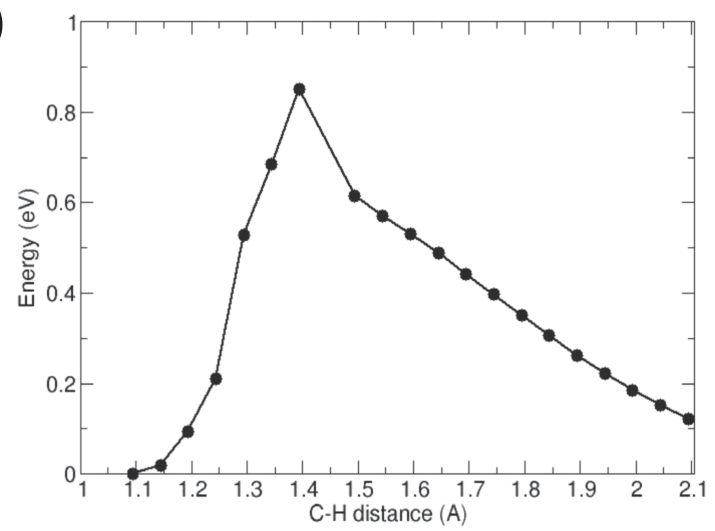

b)
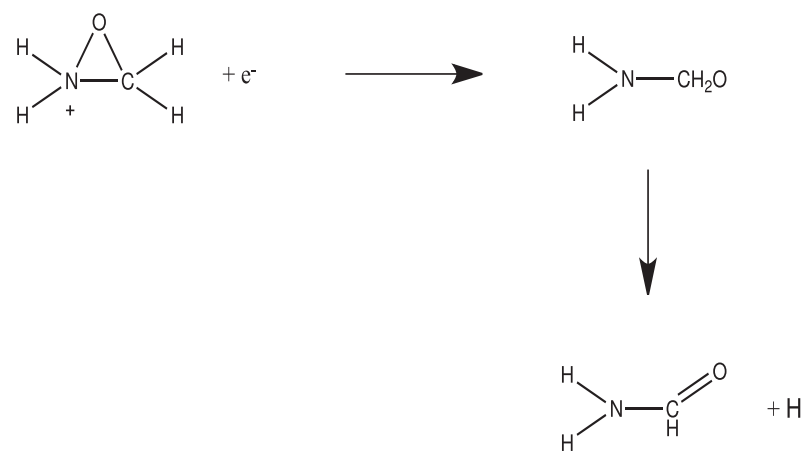

Figure 5. Mechanisms of possible reactivity of the $\mathrm{NH}_{2} \mathrm{OCH}_{2}^{+}$species. (a) Isomerizations leading to protonated formamide isomers and $\mathrm{NH}_{2} \mathrm{CO}+\mathrm{H}_{2}$ (relative energies including ZPE correction as obtained at the CCSD(T)/aug-cc-pVQZ//MP2/aug-cc-pVTZ level of theory are reported in brackets. Values are in eV); (b) recombinant dissociation process leading to neutral formamide and $\mathrm{H}$; (c) energy profile of hydrogen extraction, corresponding to the last step of the mechanism of panel (b), from $\mathrm{NH}_{2} \mathrm{CH}_{2} \mathrm{O}$ calculated at $\mathrm{CCSD}(\mathrm{T}) /$ aug-cc-pVQZ//MP2/aug-cc-pVTZ level of theory.

\section{CONCLUSIONS}

In this paper, we have shown that direct dynamics applied to bimolecular reactions can provide useful information on the reactivity responsible for the formation of organic molecules observed in the ISM. In particular, it provides a dynamical counterpart of theoretical studies that are often done by inspecting PES. Dynamics have the advantage of not imposing any reaction channels: products are observed (or not) as an outcome of the simulations. Furthermore, it is possible to study the appearance of such products as a function of collision energy. In space, ions can obtain translational velocity from different sources and this can be enough to activate some reaction channels.

By inspecting different ion/molecule reactions of neutral and protonated $\mathrm{NH}_{2} \mathrm{OH}$ with protonated and neutral $\mathrm{H}_{2} \mathrm{CO}$, respectively, we observed that it is possible to form protonated formamide in only one case, i.e., from $\mathrm{NH}_{2} \mathrm{OH}_{2}^{+}+\mathrm{H}_{2} \mathrm{CO}$. This corresponds to the reaction with the lowest activation barrier reported by Largo and co-workers (Redondo et al. 2014a), but the reaction pathway and product observed are not the same: we obtained an isomer of protonated formamide with a threemembered ring, i.e., $\mathrm{NH}_{2} \mathrm{OCH}_{2}^{+}$. If this species has enough energy, it can react: if it isomerizes, it most likely produces $\mathrm{NH}_{2} \mathrm{CO}^{+}$(a species observed in the Sgr B2(N); Gupta et al. 2013) after $\mathrm{H}_{2}$ loss. Otherwise, it can form neutral formamide via a recombinant dissociation reaction. Other ion/ molecule collisions between these reactants yield proton transfers, which occur between the ion and the neutral or within the ion using the neutral as a catalyst, or form hydroxylammonium-methanol.

Furthermore, we have studied the ion/molecule reaction of formaldehyde with ammonia. In this case we did not observe the formation of formamide, but instead observed either the formation of protonated aminomethanol or formation of $\mathrm{NH}_{2} \mathrm{CH}_{2}^{+}$. This molecule has not yet been observed, but it may be the precursor of the formation of other species observed: (1) $\mathrm{CH}_{2} \mathrm{NH}$ (observed in 1973; Godfrey et al. 1973) through a dissociative recombinant process; and (2) $\mathrm{NH}_{2} \mathrm{CH}_{2} \mathrm{CN}$ (observed in 2008; Belloche et al. 2008) by reacting with the anion, $\mathrm{CN}^{-}$, also detected recently (Agundez et al. 2010).

In conclusion, we show that direct dynamics, performed with both the computationally costly MP2 method and cheaper MSINDO semi-empirical Hamiltonian, may be a useful tool to investigate possible bimolecular reactions responsible for the formation of relatively large organic molecules in astrophysical conditions. The good performance of the semi-empirical method, which is much cheaper than ab initio or DFT methods, paves the way of using direct dynamics to study formation 
mechanisms of other relatively large molecules observed in the ISM.

We thank Paolo G. Calisse for useful discussions. We also thank ANR DynBioReact (grant No. ANR-14-CE06-0029-01) and the National Science Foundation under grant CHE1416428 for support. K.S. and A.L. thank UEVE for visiting fellowships and R.S. thanks KNUE for a visiting fellowship. K. S. also thanks to National Research Foundation of Korea (NRF, grant No. 2015-0080) for financial support. W.L.H. also acknowledges support from the Robert A. Welch Foundation under grant No. D-0005. A.L. acknowledges financial support from Junta de Castilla y Leon (Grant VA077U13).

\section{REFERENCES}

Agundez, M., Cernicharo, J., Guelin, M., et al. 2010, A\&A, 517, L2 Ahlswede, B., \& Jug, K. 1999a, JCoCh, 20, 563

Ahlswede, B., \& Jug, K. 1999b, JCoCh, 20, 572

Barone, V., Latouche, C., Skouteris, D., et al. 2015, MNRAS, 453, L31

Belloche, A., Menten, K. M., Comito, C., et al. 2008, A\&A, 482, 179

Bera, P. P., Peverati, R., Head-Gordon, M., \& Lee, T. J. 2015, PCCP, 17, 1859

Blagojevic, V., Petrie, S., \& Bohme, D. K. 2003, MNRAS, 339, L7

Bredow, T., Geudtner, G., \& Jug, K. 2009, MSINDO (Version 3.3.1) University of Bonn

Brites, V., Cimas, A., Spezia, R., et al. 2015, JChTC, 11, 871

Carruthers, G. R. 1970, ApJL, 161, L81

Chapman, S., \& Bunker, D. L. 1975, JChPh, 62, 2890

Chengalur, J. N., \& Kanekar, N. 2003, A\&A, 403, L43

Cho, Y. J., Vande Linde, S. R., Zhu, L., \& Hase, W. L. 1992, JChPh, 96, 8275

Cunningham, M. R., Jones, P. A., Godfrey, P. D., et al. 2007, MNRAS, 376, 1201

Darren Dowell, C., Hildebrand, R. H., Schleuning, D. A., et al. 1998, ApJ, 504,588

Ditchfield, R., Hehre, W. J., \& Pople, J. A. 1971, JChPh, 54, 724

Dunning, T. H. 1989, JChPh, 90, 1007

Fourikis, N., Sinclair, M. W., Robinson, B. J., et al. 1974, AuJPh, 27, 425

Frisch, M. J., Trucks, G. W., Schlegel, H. B., et al. 2009, Gaussian 09 (Wallingford, CT: Gaussian Inc)

Garrod, R. T., Widicus Weaver, S. L., \& Herbst, E. 2008, ApJ, 682, 283

Gilmore, W., Morris, M., Palmer, P., et al. 1976, ApJ, 204, 43

Godfrey, P. D., Brown, R. D., Robinson, B. J., \& Sinclair, M. W. 1973, ApL, 13,119

Gottlieb, C. A. 1973, in Detection of Acetaldehyde in Sagittarius Molecules in the Galactic Environment, ed. M. A. Gordon \& L. E. Snyder (New York: Wiley-Interscience), 181
Gottlieb, C. A., Palmer, P., Richard, L. J., \& Zuckerman, B. 1973, ApJ, 183,699

Gupta, H., Gottlieb, C. A., Lattanzi, V., et al. 2013, ApJL, 778, L1

Halfen, D. T., Ilyushin, V., \& Ziurys, L. M. 2011, ApJ, 743, 60

Hase, W. L., Duchovic, R. J., Hu, X., et al. 1996, QCPE, 16, 671

Herbst, E. 1982, CP, 65, 185

Herbst, E. 1985a, ApJ, 291, 226

Herbst, E. 1985b, ApJ, 292, 484

Hollis, J. M., Lovas, F. J., \& Jewell, P. R. 2000, ApJL, 540, L107

Hollis, J. M., Lovas, F. J., Remijan, A. J., et al. 2006, ApJL, 643, L25

Huntress, W. T., \& Mitchell, G. F. 1979, ApJ, 231, 456

Jones, B. M., Bennet, C. J., \& Kaiser, R. 2011, ApJ, 734, 78

Jones, P. A., Cunningham, M. R., Godfrey, P. D., \& Cragg, D. M. 2007, MNRAS, 374, 579

Kahane, C., Ceccarelli, C., Faure, A., \& Caux, E. 2013, ApJL, 763, L38

Kaiser, R. I. 2002, ChRv, 102, 1309

Kaiser, R. I., Parker, D. S. N., \& Mebel, A. M. 2015, ARPC, 66, 43

Kuan, Y.-J., Charnley, S. B., Huang, H. C., et al. 2003, ApJ, 593, 848

Larsson, M., Geppert, W. D., \& Nyman, G. 2012, RPPh, 75, 066901

Lopez, J. G., Vayner, G., Lourderaj, U., et al. 2007, JACS, 129, 9976

Lovas, F. J., Hollis, J. M., Remijan, A. J., \& Jewell, P. R. 2006, ApJL, 645, L137

Ohishi, M., Ishikawa, S., Amano, T., et al. 1996, ApJL, 471, L61

Petrie, S., \& Bohme, D. K. 2007, Mass Spectrom. Rev., 26, 258

Quan, D., \& Herbst, E. 2007, A\&A, 474, 521

Raghavachari, K., Trucks, G. W., Pople, J. A., \& Head-Gordon, M. 1989, CPL, 157,479

Redondo, P., Barrientos, C., \& Largo, A. 2014a, ApJ, 780, 181

Redondo, P., Barrientos, C., \& Largo, A. 2014b, ApJ, 793, 32

Remijan, A. J., Snyder, L. E., McGuire, B. A., et al. 2014, ApJ, 783, 77

Rubin, R. H., Swenson, G. W., Jr., Solomon, R. C., \& Flygare, H. L. 1971, ApJL, 169, L39

Sato, F., Hasegawa, T., Whiteoak, J. B., \& Miyawaki, R. 2000, ApJ, 535,857

Sloane, C. S., \& Hase, W. L. 1977, JChPh, 66, 1523

Snow, J. L., Orlova, G., Blagojevic, V., \& Bohme, D. K. 2007, JACS, 129,9910

Snyder, L. E., Lovas, F. J., Hollis, J. M., et al. 2005, ApJ, 619, 914

Spezia, R., Salpin, J.-Y., Gaigeot, M.-P., Hase, W. L., \& Song, K. 2009, JPCA, 113,13853

Sun, L., Song, K., \& Hase, W. L. 2002, Sci, 296, 875

Swope, W. C., Andersen, H. C., Berens, P. H., \& Wilson, K. R. 1982, JChPh, 76,637

Tercero, B., Kleiner, I., Cernicharo, J., et al. 2013, ApJL, 770, L13

Turner, B. E. 1989, ApJS, 70, 539

Whiteoak, J. B., \& Gardner, F. F. 1983, MNRAS, 205, 27

Woon, D. E. 1999, Icar, 142, 550

Woon, D. E. 2001a, IJQC, 88, 226

Woon, D. E. 2001b, Icar, 149, 277

Woon, D. E., \& Dunning, T. H. 1993, JChPh, 98, 1358 